UCRL- 96569

PREPRINT

\title{
A LOW JITTER, LOW COST TIME-OF-FLIGHT CIRCUIT
}

M. D. Cable

M. S. Derzon

R. G. Vietra

H. P. Sprackien

This paper was prepared for submittal to the IEEE 1987 Nuclear Science Sympostum, San Francisco, California, October 21-23, 1987

October 1987

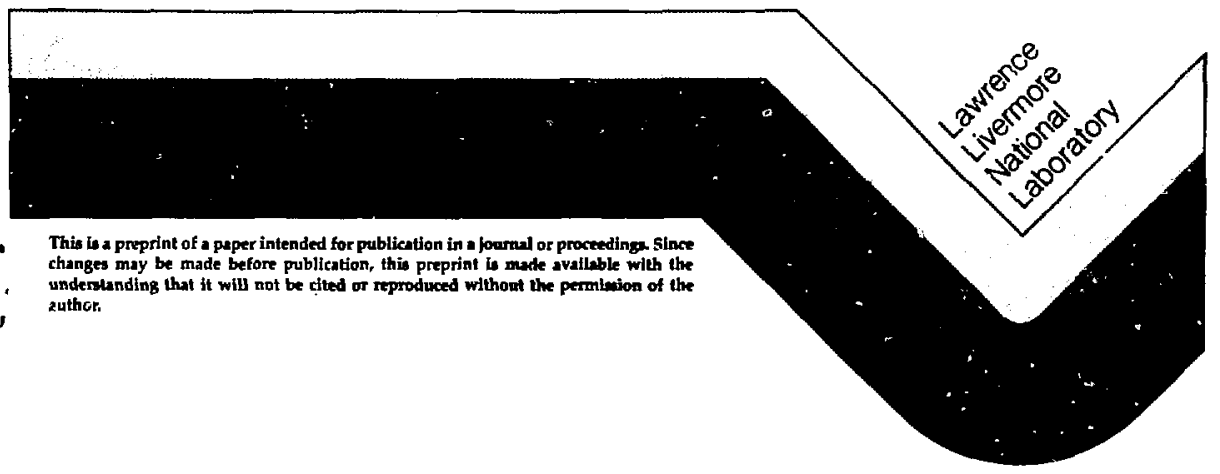


M. D. Cable. M. S. Derzon, and R. G. Vteira

H. P. Spracklen, P.E.. Consultant

University of California

Lamence Livermore Hational Laboratory

P. 0. Box 5508, Livermore, Californta

\section{Abstract}

A lor cost circuit has been developed for use In a neutron time-of-flight spectroneter at the Nova Laser Facility. Using a silicon charged-perticle detector, amplifier and constant-fraction df seriminator, timing resolution of better than 50 ps FWHM has been achleved. Using an array of many such detectors, very high data rates and precise spectra can be obtained.

\section{Introduction}

In order to determine fusion fuel ior temperatures and fuel compression for Inertial Conf inement Fusion (ICF), the energy fistribution of fusion neutrons must be measured accurately. This energy distribution can be measured by neutron time-of-flight techniques which require detector to record arrival $t$ imes of the neutrons at the end of a known flight path. In our detector. the neutrons coll1de with a thin polyethylene sheet, elastically scattering protons. An array of sall ",ingle-hit" silicon detectors and circuity with recovery times on the order of 5 ns can be used such that each records the arrival time of one neutron (proton flight path is negligibly small). An energy distribution is then constructed from which the ion temperature $\left(\theta_{i}\right)$ and fuel areal density ( $\angle \mathrm{ph}\rangle)$ can be obtained. The $\theta_{i}$ is expressed as $\Delta \mathrm{E}=177 \sqrt{\theta_{i}}$, where $\triangle E$ is the FHFM energy spread of the primary $14 \mathrm{MeV}$ nefutron burst. Feel areal density can be measured by obtaining detailed spectra of neutrons produced in secondary fusion reactions which have energles signifteantly different from the primary neutrons.

Methods to obtain these quantities in the past have consisted of activation techniques or use of a single detector and oscillascope with which it is impossible to unfold data with sufficient accuracy. Silicon ctrip detectors or small (5 $\mathrm{mm} \times 5 \mathrm{~mm}$ ) single detectors have the advantages of speed [low capacitance) and ability to detect single events.

The conponents to construct a large array of single detectors (individual detectors are referred to as "channels") need to be saali and relatively inexpensfue oer channel. Stlicon detectors, I GHz MHIC amplifiers, and an ECL compatible constent-fraction discriminator (CFD) have been designed in a small, economical configuration that achieves 35 ps (Fulf) tining resolution--quite adequate for accurate $\theta_{i}$ and $\langle\rho R>$ measurements [1]. The stgnal is then run into a fast $t$ ime-to-digital convarter (TDC), and the arrival tine is recorded relative to a comon start. trigger.

\section{Description}

The detector is a $5 \mathrm{~mm} \times 5 \mathrm{~mm} \times 210 \mu \mathrm{m}$ piece of $\mathrm{N}$-type $\mathrm{s}$ ificon with a thin ion-implanted p-region. The 210 um thickness was chosen as a compromise between signal rise time and the amount wi energy that will be deposited in the detector as the charqed particle passes through it.

Fork performed under the auspices of the U.S. Department of Energy by the Laurence Livermore Hat ional Laboratory under contract number H-7405-ENG-48.

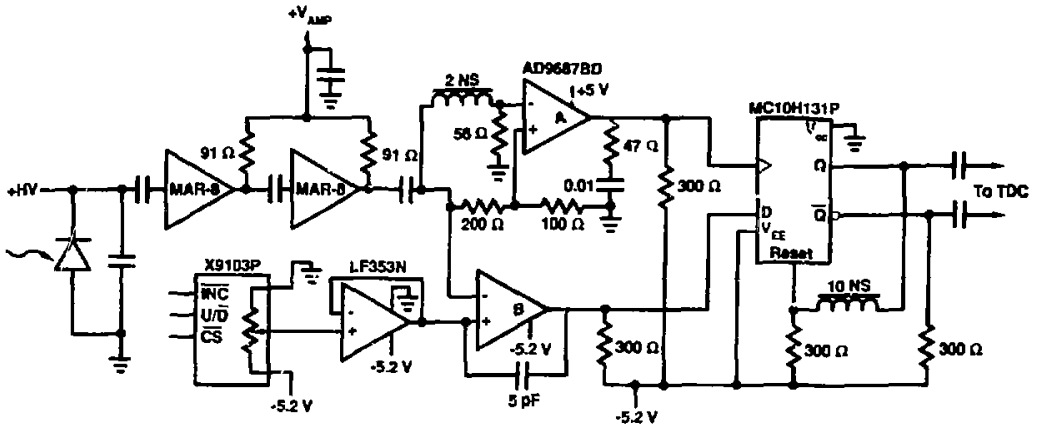

Flgure 1. Time-of-flight circuit. 
The amplifier section is comprised of 2 cascaded mornolithic amblifiers, each having a theoret ical qain of $21 \mathrm{~dB}$ and a $3.5 \mathrm{dBn}$ nofse fiqure--both at $1 \mathrm{GHz}$. They are 0.085" in diameter so a compact desigr can be achteved. Over an inout ranqe of between 0.5 and $6 \mathrm{MeV}$, the output of the combined amps yields $150 \mathrm{mV}$ to 2.6 volts (see Fiq. 1).

From the amplifiers, the signal is split to the constant-fraction discriminator (A) and to the gate comparator (B). The CFD is of standard design, using a $2 \mathrm{~ns}$ delay on one side and 33 percent attenuation on the other. The gate comparator is set for a threshold above the noise so as only to enable the flip-flop during a real event. This allows the CFD comparator threshold to be set a 0 volts.

Once enabled and then clocked, the flip flop is latched for? $10 \mathrm{~ns}$ before being reset as is required by the IDC (see Fig. 2). The TOC is stopped by this logic siqnal. Its comon start input is generated from a Nova laser pickoff, and is therefore relative to the time neutrons will emerge from an imploded ICF $t$ arget. The time between the start and stop is recorded and read out via CAMAC--thus qiving an absolute ToF for the incident neutron.

A diqitally controlled circuit can be used to set the gate comparator's thresho?d. This is especially useful in larqe arrays.

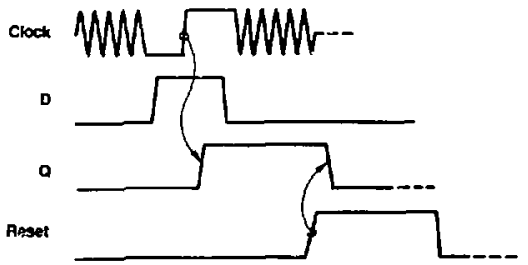

Figure 2. Timing Diagram at MClOH13)P flip-flop.

\section{Measurements}

For initial testing, a laser light pulser was used for the input to the detector. A time-to-analog converter, together with a oulse height analyzer was used to check for timing jitter. The system resolu- tion was < 3 channels (e 15 ps) FHH. The light intensity was yarled over a range of $825 \mathrm{keV}$ to 5.8 HeV. With this system, 5 os/channel time bins were achieved and a $7+1$ channe, fHH spectrum was observed. This translates to $35 \pm 5$ os timing resolution.

To measure absolute jitter with neutrons, another experiment is planned. By putting 2 detectors face to face, an energet ic proton $(10-12 \mathrm{MeV}) \mathrm{will}$ pass through both detectors, creating a signal in each. The second detector's signal will be used to start the TOC ind the first used to stop it, thereby cetting up a coincidence measurement to count only protons that Dass through both detectors. Any system jitter will be cancelled, theoretically, if both signais are processed identically. This will then yjeld the true jitter in the circuit.

\section{Cost}

The cost of circuit components, including the detector total about $\$ 90$ per channel. The TDC is about $\$ 250$ per channel. A further savings can be achieved by having several channels share a TDC channel. The cost of the PC board will vary dependent upon the number of channels per board.

\section{Sumary}

A low cost, low jitter circuit has been aesigned and implemented achieving better than 50 os FWH ciming resolution. The 35 pS FWH measurenent was done with a light pulser. He expect with neutrons to see this number deqrade slightly due to the charqe sweep-out time for the ionization track left by the proton (as opposed to surface ionization for the light pulser).

This approach can also be used to ach feve very high data rates at accelerators because the data mould be collected in parallel from many inexpensive channels. Then, using a high throughput bus architecture such as FASTEUS to move the collected data, rates could increase to many times the maximum achievable with a single detector.

\section{References}

[I] M. 0. Cable, S. P. Hatchett, J. App 1. Phys., 62, p. 2 r.33 (1987).

[2] M. D. Cahie, J. Appl. Phys., 60, p. 3068 (1986).

[3] H. Spieler, IEEE Trans. Nucl. Scl. NS-29, p. $1142(1982)$.

\section{DISCLAIMER}

This Iopon was prepared as an accounl ni wort sponsored by an agency of the United States Government. Neither the United States Government nor any agency thereof, nor uny of their employees, makes any warranty. exprass or implied, or assumes any legal liability or responsibility for the accuracy. completeness, or usefulness of any information, apparalus, product, of prociss disclosed, or represents that its use would not infringe prvately owned rights. Reference herein to any specific comenercial product, process, or service by trade name, trademark. manufacturec, or otherwise does nol nesessarily constitute of impl is endorsement, recom. mendation, or favoring by the United States Govemment or any agency thercor. Time views and opinions of authors expressed berein do not necessurily state of reflect those of the Uniled States Governmant or any agency theraot. 